\title{
Optimal Design of Single-phase 12S-6P FEFSM Using Segmental Rotor and Non-Overlap Windings
}

\author{
Mohd Fairoz Omar, Erwan Sulaiman, Hassan Ali Soomro, Faisal Amin, Laili Iwani Jusoh, \\ Enwelum I Mbadiwe \\ ${ }^{1}$ Research Center for Applied Electromagnetics (EMCenter), Universiti Tun Hussein Onn Malaysia (UTHM), \\ 86400 Parit Raja, Johor, Malaysia
}

\begin{tabular}{l} 
Article Info \\
\hline Article history: \\
Received Sep 29, 2018 \\
Revised Dec 20, 2018 \\
Accepted Jan 11, 2019 \\
\hline
\end{tabular}

\section{Keywords:}

Field excitation

Flux switching machine

Optimization

Segmental rotor

Single-phase

\begin{abstract}
Recently, a three-phase Field Excitation Flux Switching Motor (FEFSM) using salient rotor has been introduced, suitable for high torque, high power as well as high speed diverse performances due to their advantages of easy rotor temperature elimination and controllable field excitation (FE) flux. However, existing FEFSMs are found to have low torque performance as the salient rotor structure has caused longer flux path, and consequently weak flux linkage. Therefore, a new structure of a single-phase FEFSM using segmental rotor and non-overlap windings is proposed. There are two valuable findings found in this topology, first is less copper loss due to the non-overlap windings between armature and FE coils, and secondly the segmental rotor structure has produces shorter flux path to produce high torque, less rotor weight as well as robust rotor at high speed condition. Flux linkage, back-emf, average torque and output power characteristics of the initial and optimized designs have been investigated and compared using 2D Finite Element Analysis (2D-FEA) through JMAG Designer version 15. Based on the 2D-FEA analysis, the average torque has increased by $81.3 \%$ to $1.65 \mathrm{Nm}$, while the output power of $466.5 \mathrm{~W}$, increased of $68.2 \%$. In conclusions, a FEFSM using segmental rotor and non-overlap windings is considered as the best single-phase motor due to their optimal performances and less copper loss.
\end{abstract}

Copyright $(2019$ Institute of Advanced Engineering and Science. All rights reserved.

\section{Corresponding Author:}

Mohd Fairoz Omar, Research Center for Applied Electromagnetics (EMCenter),

Universiti Tun Hussein Onn Malaysia (UTHM),

86400 Parit Raja, Johor, Malaysia.

Email: fairoz.omar@yahoo.com

\section{INTRODUCTION}

The first concept of flux switching machine (FSM) was founded and published in 1950. FSM consists of all flux sources in the stator. Besides the advantage of brushless machines, FSM has a single piece of iron rotor structure allowing to be apply in robust and high-speed applications [1]. Over the past ten years, many new FSM topologies have been developed for various applications, ranging from low-cost domestic appliances, automotive, wind power, aerospace, and others [2], [3].

Figure 1 illustrates the basic operation of FSM. Considering Figure 1(a), the excitation of the field and armature windings at positive current creates a flux vector in the north-westerly direction and north-easterly direction, respectively. The combined flux generated by the two coils caused a flux moving vertically upwards and the rotor aligned itself with a pair of vertical stator. Additionally, Figure 1(b) illustrates the current in the armature winding is reversed, while the FEC winding continues being excited in the same direction by the effect of the $180^{\circ}$ flux shifting from west-south [4]. 


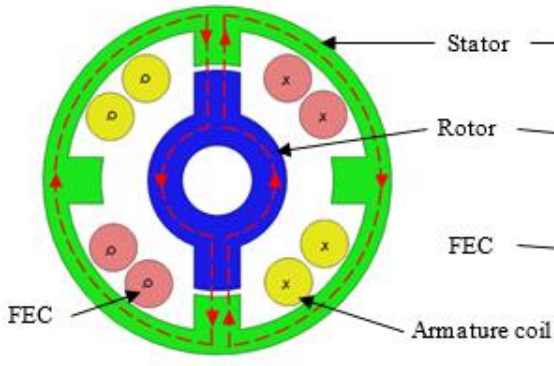

(a)

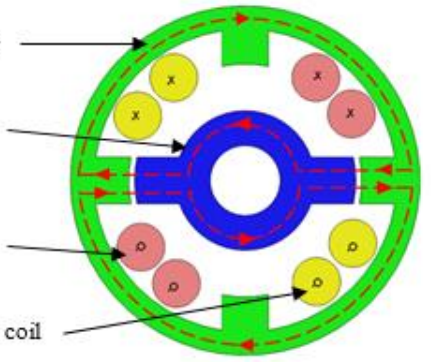

(b)

Figure 1. Operating principle of FEFSMs

The result from the $180^{\circ}$ shifting makes the rotor tends to align with the stator poles based on the flux movement in a westerly direction through horizontal stator poles. Therefore, each reversal of current directions in the armature causes the stator flux vector to switch between horizontal and vertical directions, hence introducing the name FSM [5].

Generally, FSM can be categorised into three groups: permanent magnet flux switching motor (PMFSM), field excitation flux switching motor (FEFSM), and hybrid excitation flux switching motor (HEFSM). PMFSM and FEFSM using PM and field excitation coil (FEC), respectively, as their main flux sources, while HEFSM combines both PM and FEC as its main flux source. Compared to these three types of FSM, FEFSM has shown significant advantages due to low manufacturing cost, and demagnetization can be neglected because of FEFSM is magnet-less machine. In addition, the magnetic field produced by the FECs can be controlled allowing FEFSM suitable to be utilized on various equipments [6]-[8].

Figure 2 shows the example of three-phase and single-phase salient rotor FSM with overlap windings configurations. The author [9] introduced a new structure of three-phase 24S-10P FEFSM with overlapping windings between 12 armature coils and 12 FEC coils as illustrated in Figure 2(a). With a single polarity of the FEC winding, the motor becomes easy to construct, and produces less flux leakage. This motor is suitable for industrial applications which require high torque and power capability [10], [11]. This is because of its high torque and power of $240.5 \mathrm{Nm}$ and $25.7 \mathrm{~kW}$, respectively at base speed of $1,200 \mathrm{rpm}$.

Figure 2(b) shows the single-phase salient rotor 12S-6P FEFSM. The proposed motor is introduce in order to solve the problem of high cost consumption in PMFSMs technology [12]. The stack length and stator outer diameter are set to $25 \mathrm{~mm}$ and $90 \mathrm{~mm}$, respectively. This motor has 12 slots, in which 8 slots accommodate 4 non-overlap FECs and each slot from the remaining 4 slots is divided into 2 to form 4 overlap armature coils. Consequently, the motor has shorter end windings, and better copper usage.

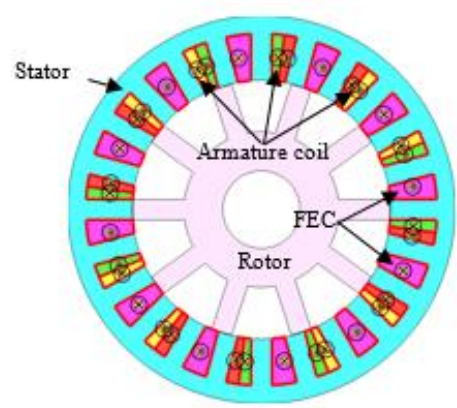

(a)

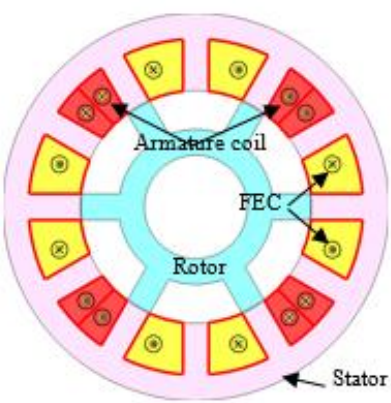

(b)

Figure 2. FEFSM with salient rotor (a) 3-phase 24S-10P and (b) Single-phase 12S-6P

However, the salient rotor structure of existing FEFSM produces longer flux path, higher rotor volume, and increase the rate of iron loss. In addition, the overlap winding technique applied between armature coils and FECs has produced high volume of motor and reduce low torque density. Besides, high copper wire consumption has produced high copper loss and reduces the efficiency.

This paper presents a new single-phase segmental rotor 12S-6P FEFSM with non-overlap windings. The proposed motor has 12 slots for armature coils winding, 12 slots for FECs winding and 6 segmental rotors 
that provide a short flux path from the stator to the rotor and vice versa. Consequently, the proposed motor enables higher flux yields and increases the output torque. 2D-Finite Element Analysis (FEA) through JMAG Designer version 15 is used to investigate the coil test, flux linkage, flux line, back-emf, average torque and output power characteristics of the proposed motor.

\section{DESIGN RESTRICTIONS AND SPECIFICATIONS OF THE INITIAL DESIGNED}

The initial design restriction is illustrated in Table 1 and Figure 3 demonstrates the structure of singlephase segmental rotor 12S-6P FEFSM with non-overlap windings. The maximum of armature current density, $J_{A}$ and field excitation current density, $J_{E}$ are set to $30 \mathrm{~A}_{\mathrm{rms}} / \mathrm{mm}^{2}$ and $30 \mathrm{~A} / \mathrm{mm}^{2}$, respectively. The electrical silicon steel 35A250 material is used for stator and rotor body. While, stator outer diameter, rotor outer diameter, shaft diameter and air gap are restricted to $75 \mathrm{~mm}, 45 \mathrm{~mm}, 30 \mathrm{~mm}$ and $0.5 \mathrm{~mm}$, respectively. The single rotor structure with stack length of $20.3 \mathrm{~mm}$ is mechanically robust because it consists only of stacked electromagnetic sheets.

Table 1. Design Restriction and Specifications of the Initial Design

\begin{tabular}{lcc}
\hline \multicolumn{1}{c}{ Parameter } & Value & Unit \\
\hline Maximum DC current & 7.5 & $\mathrm{~A}$ \\
Maximum armature current & 10.5 & $\mathrm{~A}$ \\
Maximum $J_{A}$ & 30 & $\mathrm{~A}_{\mathrm{rms}} / \mathrm{mm}^{2}$ \\
Maximum $J_{E}$ & 30 & $\mathrm{~A} / \mathrm{mm}^{2}$ \\
Stator outer diameter & 75 & $\mathrm{~mm}$ \\
Rotor outer diameter & 45 & $\mathrm{~mm}$ \\
Stack length & 20.3 & $\mathrm{~mm}$ \\
Air gap & 0.25 & $\mathrm{~mm}$ \\
Shaft diameter & 30 & $\mathrm{~mm}$ \\
Number of FEC turn & 93 & turn \\
Number of armature turn & 93 & turn \\
\hline
\end{tabular}

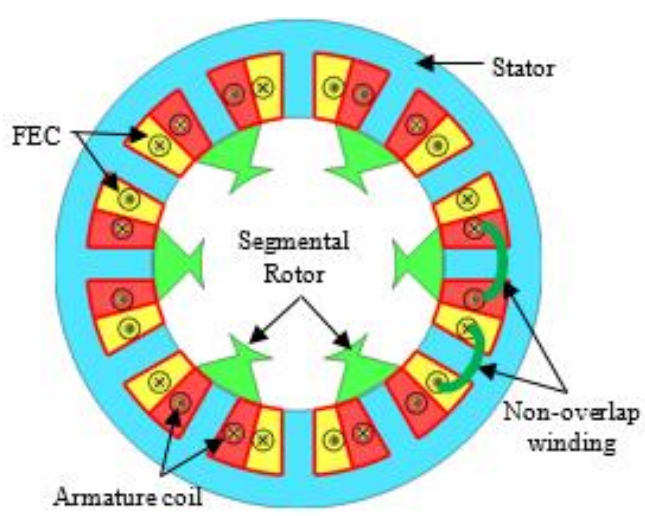

Figure 3. Initial structure of the proposed FEFSM

\section{PERFORMANCES OF INITIAL DESIGN OF FEFSM}

\subsection{Coil test}

Result of the proposed single-phase 12S-6P FEFSM using segmental rotor coil test is depicted in Figure 4, at the point when $J_{A}$ and $J_{E}$ are set to maximum of $30 \mathrm{~A}_{\mathrm{rms}} / \mathrm{mm}^{2}$ and $30 \mathrm{~A} / \mathrm{mm}^{2}$, respectively and rotor is shifted by $45^{\circ}$ mechanical. Clearly, the flux linkage at highest $J_{A}$ is $0.0718 \mathrm{~Wb}, 39.4 \%$ higher than magnetic flux at maximum $J_{E}$. However, the magnetic flux profile shows unbalance flux between positive and negative cycles due to flux leakage occurs at $230^{\circ}$ to $310^{\circ}$ electric when flux attempt to flow from stator to rotor. Besides, the flux linkage of $J_{E}$ only is slightly lower than flux linkage of $J_{A}$ due to magnetic flux generated from FEC will move around the stator and rotor before reaching the armature windings. The flux linkage of FEC lead $90^{\circ}$ 
of armature coil flux linkage, hence ensuring the motor to be worked based on standard operating principle of single-phase motor.

\subsection{Result of Flux Line}

Figure 5 delineates the flux line delivered under maximum $J_{E}$ of $30 \mathrm{~A} / \mathrm{mm}^{2}$ at $0^{\circ}$ or $360^{\circ}, 90^{\circ}, 180^{\circ}$, and $270^{\circ}$ electric cycle. Figure 5 (a) and (c) demonstrate the magnetic field streams from the stator to the rotor and back to stator seem shorter at all armature coils to form one complete magnetic flux cycle. Besides, the flux line profile also indicates the highest flux linkage achieved is at $180^{\circ}$, proven through flux characteristics at coil test as illustrated in Figure 4. Concentrated flux is highlighted with red circles in Figure 5 (b) and (d) because flux does not legitimately flow to form one complete cycle due to incomplete magnetic flux paths that connects the adjacent stator teeth. In addition, the flux line also proved the condition of zero rotor position in which the magnetic flux is zero when the rotor positions at $90^{\circ}$ and $270^{\circ}$.

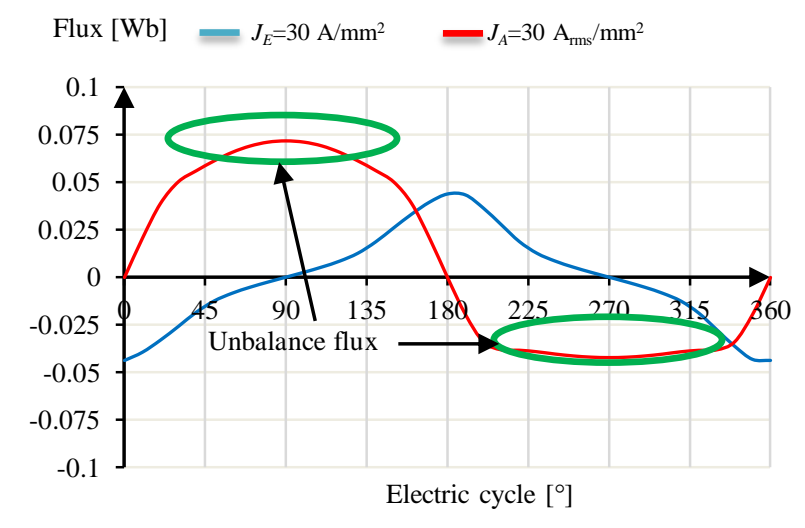

Figure 4. Flux linkage in open-circuit test

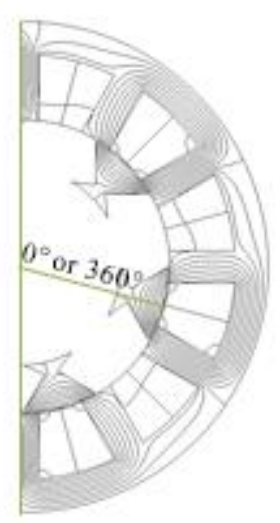

(a)

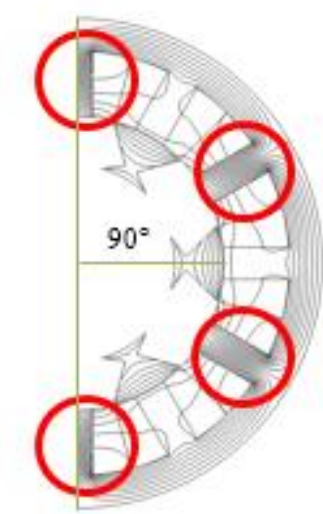

(b)

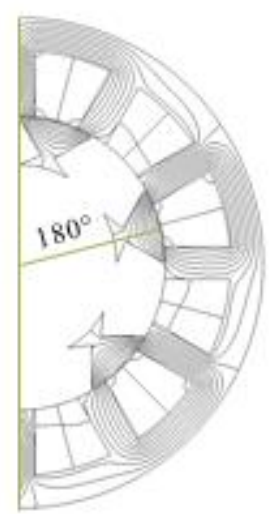

(c)

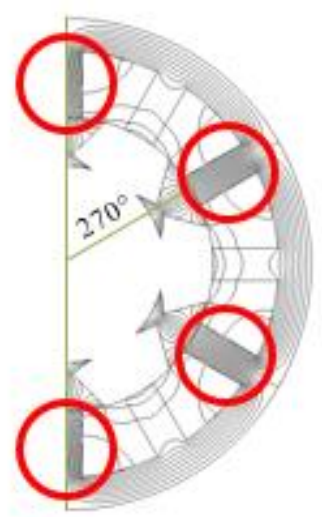

(d)

Figure 5. FEC flux line at 4 electric cycle positions, (a) $0^{\circ}$ or $360^{\circ}$, (b) $90^{\circ}$, (c) $180^{\circ}$ and (d) $270^{\circ}$

\subsection{Result of Back-emf}

Figure 6 shows back-emf of the proposed single-phase 12S-6P FEFSM. The highest amplitude of back-emf is $13.4 \mathrm{~V}$. From the figure the back-emf has high distortion between $45^{\circ}$ to $135^{\circ}$ and $215^{\circ}$ to $335^{\circ}$ electric cycle due to high 3rd and 5th of total harmonic distortion (THD). In addition, the unsmooth sinusoidal of $J_{E}$ flux linkage as illustrated in Figure 4 also led to high THD. 


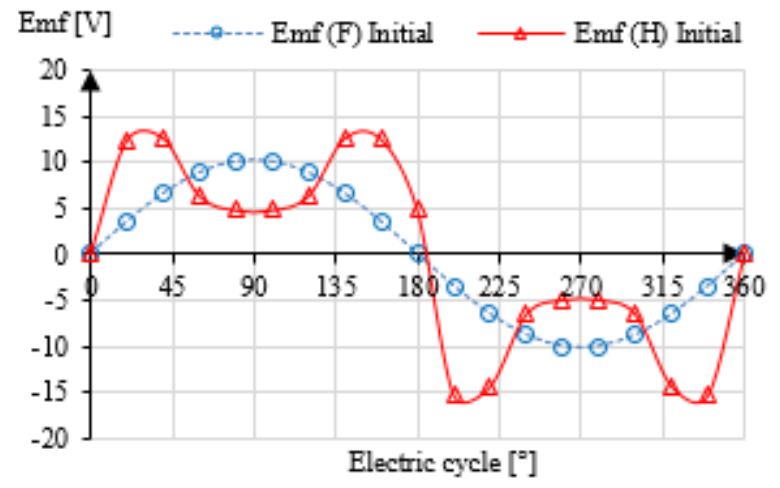

Figure 6. Back-emf of the proposed single-phase 12S-6P FEFSM

\subsection{Initial Performances of Torque and Power}

The initial design has produced torque and power of $0.91 \mathrm{Nm}$ and $277.5 \mathrm{~W}$, respectively at based speed of 2,899 rpm. The performance of torque and power decreased proportionally with increase of speed, which is at medium speed region of 4,000 rpm, the torque produced is $0.65 \mathrm{Nm}$ and the power achieved is 269 $\mathrm{W}$. While at high speed region of $8,000 \mathrm{rpm}$, the torque produced is $0.27 \mathrm{Nm}$ and the equivalent power obtained is $245 \mathrm{~W}$.

\section{12S-6P FEFSM IN DESIGN OPTIMIZATION}

In order to improve the performance of torque and power, the optimization process is carried out by using deterministic optimization technique. The deterministic optimization technique is also expected to solve the problem of back-emf disruption, unbalanced flux of armature current only and unsmooth FE flux linkage.

Figure 7 shows the procedures of deterministic optimization method. From the figure, each optimization cycle is divided into 3 stages namely rotor, armature slot and FEC slot. To determine whether the optimization process is achieved or not, the determination process is performed by comparing the torque optimized, Topt at the end of each cycle with the torque performance of the previous cycle, Tci. Generally, there are seven parameters involved in the optimization process: $R_{1}, R_{2}, R_{3}, A_{1}, A_{2}, F_{1}$, and $F_{2}$ as illustrated in Figure 8. In addition, it should be noted in the optimization process, the following parameters need to be maintained as initial parameter: outer radius of stator $\left(S_{o}\right)$, armature and field excitation number of turns $\left(N_{A}\right.$ and $N_{E}$ ), air gap $\left(A_{g}\right)$ and current input of armature and field excitation $\left(I_{A}\right.$ and $\left.I_{E}\right)$. Table 2 illustrates the comparison between initial and optimized design specifications. Obviously, parameters such as $S_{o}$ and $A_{g}$ are maintained, while ratio between the rotor outer radius, $R_{l}$ and the stator outer radius, $S_{o}$ decreased from 0.59 to 0.56 . From the table, parameters $A_{1}$ and $F_{1}$ have increased, while parameters of $A_{2}$ and $F_{2}$ have decreased due to the 93 number of turns for both slots are remains unchanged until the highest torque value is achieved. In addition, segmental rotor span, $R_{2}$ shows the highest change of $66.7 \%$ from 15 degrees to 25 degrees. This proves that the use of segmental rotor has influenced the flux linkage interaction between stator and rotor.

\subsection{Result of $J_{E}$ and $J_{A}$ Flux Linkage}

Figure 9 shows the flux linkage comparison between initial and optimized designs of single-phase FEFSM using segmental rotor. Clearly, the flux linkage profile at maximum $J_{E}$ is more sinusoidal and increases by $64 \%$ from $0.0435 \mathrm{~Wb}$ to $0.0714 \mathrm{~Wb}$. While, the flux linkage at maximum $J_{A}$ shows a more balance than the initial design because of the ratio between positive and negative amplitudes has been reduced by $32.3 \%$ from 1.7 to 1.15 . In addition, the maximum flux linkage for $J_{A}$ is $0.11 \mathrm{~Wb}, 35.5 \%$ higher than the flux linkage at maximum $J_{E \text {. }}$

Figure 9 shows the flux linkage comparison between initial and optimized designs of single-phase FEFSM using segmental rotor. Clearly, the flux linkage profile at maximum $J_{E}$ is more sinusoidal and increases by $64 \%$ from $0.0435 \mathrm{~Wb}$ to $0.0714 \mathrm{~Wb}$. While, the flux linkage at maximum $J_{A}$ shows a more balance than the initial design because of the ratio between positive and negative amplitudes has been reduced by $32.3 \%$ from 1.7 to 1.15 . In addition, the maximum flux linkage for $J_{A}$ is $0.11 \mathrm{~Wb}, 35.5 \%$ higher than the flux linkage at maximum $J_{E}$. 


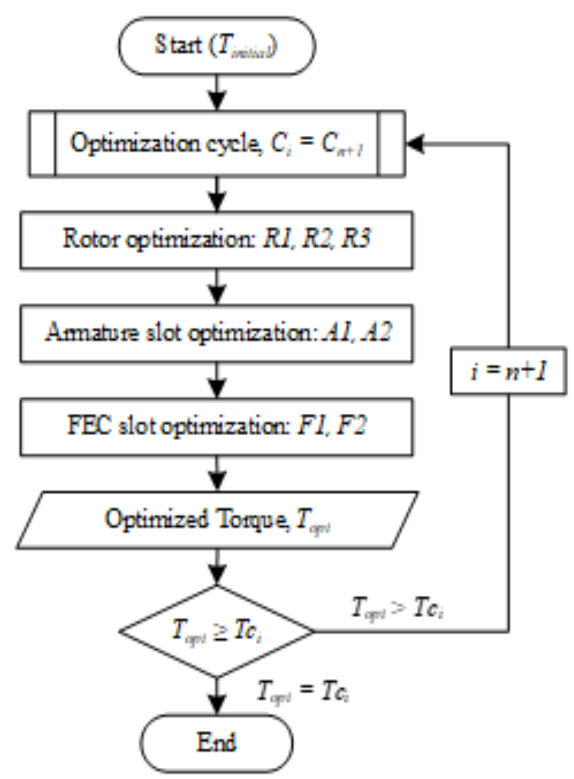

Figure 7. Optimization process

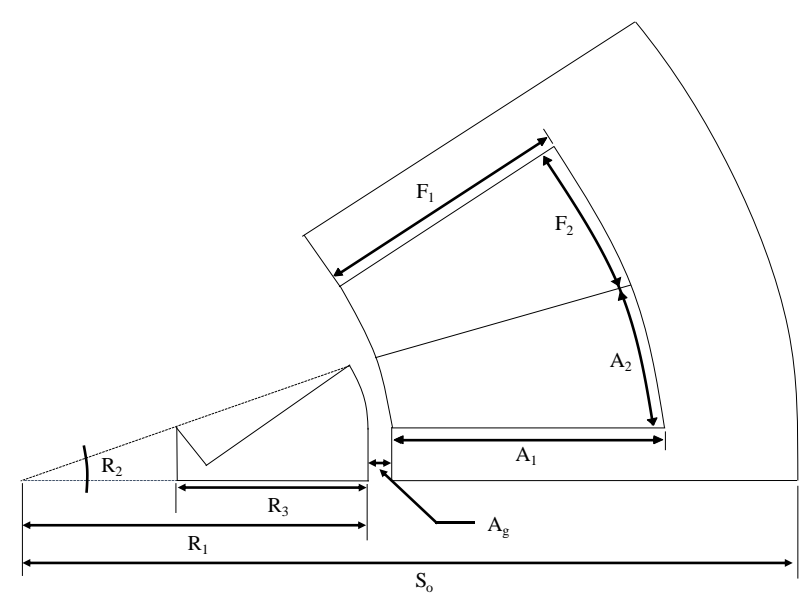

Figure 8. Parameter sensitivities in optimization processes

\subsection{Result of Back-emf}

The back-emf result of both designs is illustrated in Figure 10. Both back-emf readings are taken when the speed is set at $500 \mathrm{rpm}$. From the figure, the highest amplitude of the back-emf after optimization is $24.9 \mathrm{~V}$ and shows an increase of $85.7 \%$ from the initial design amplitude. This happens because of $J_{E}$ flux linkage is increased. However, the back-emf profile shows a lot of improvement, especially distortion in harmonic number 3 and 5 have decreased by $78.5 \%$ and $84.4 \%$, respectively as illustrated in Figure 11.

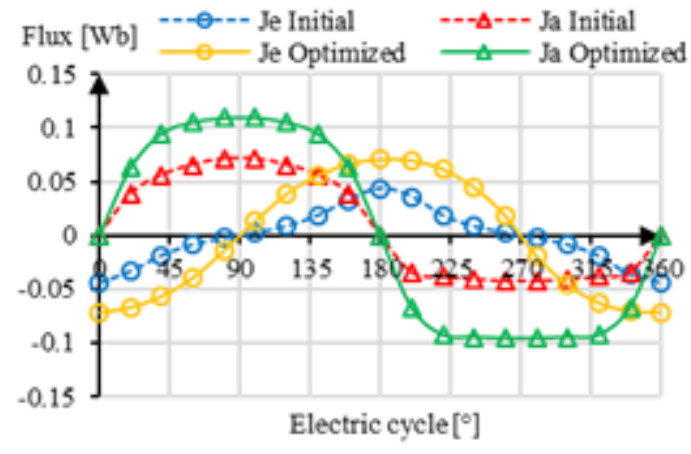

Figure 9. Flux linkage of 12S-6P FEFSM

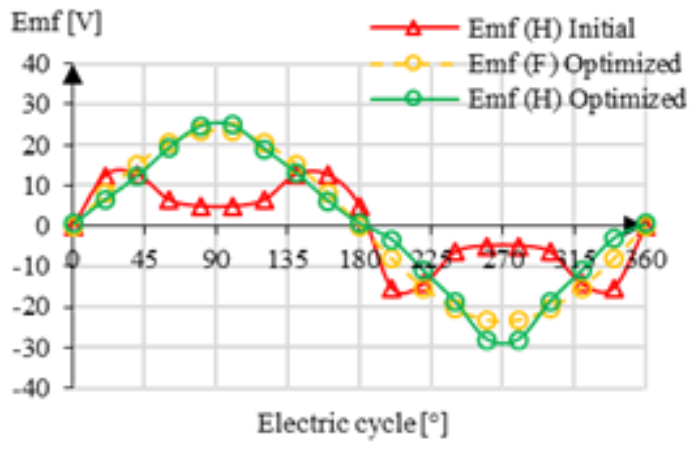

Figure 10. Back-emf of optimization 12S-6P FEFSM

\subsection{Flux Distribution}

Figure 12 shows flux distribution when the motor is given the maximum armature current, $I_{A}$ and rotor at $270^{\circ}$ electric cycle. From Figure 12(a), the flux distribution of initial design indicates a lot of flux leakage on each side of armature coil tooth. This happens because of segmental rotor span is not sufficiently large has caused flux from stator to rotor unable to flow and leak out from the flux path. Figure 12(b) shows the flux distribution after the optimization process is performed. The larger segmental rotor span allows flux to flow between two stator teeth and one segmental rotor and reduce flux leakage and enhance flux concentration. It also proved the result of flux linkage as shown in Figure 9 is acceptable, which is the issue of unbalanced flux has been solved due to the ratio between positive and negative amplitudes of armature flux has been reduced. 
Table 2. Design Specifications of the Initial and Optimized Design

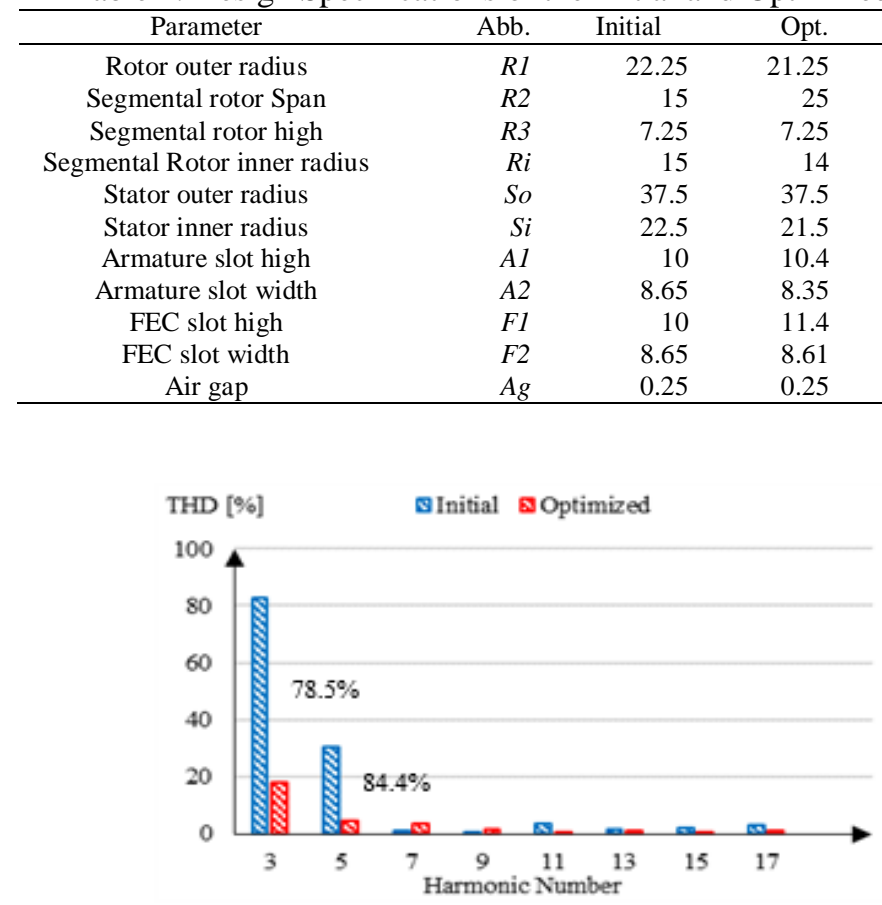

Figure 11. THD versus harmonic number

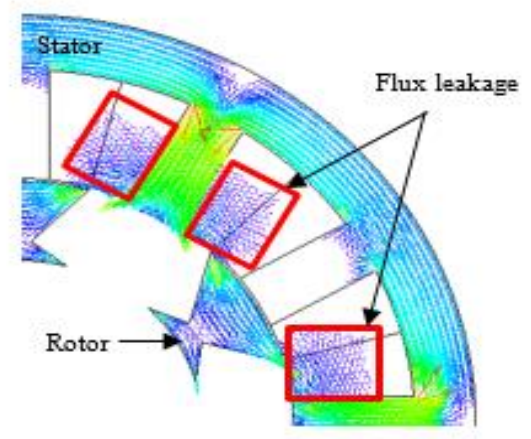

(a)

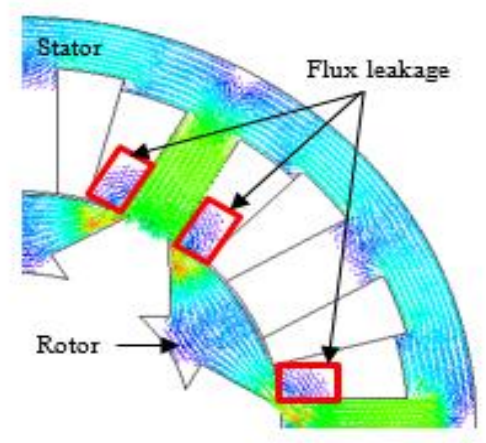

(b)

Figure 12. Flux distribution of single-phase FEFSM, (a) initial design, and (b) optimized design

\subsection{Various Torque at Various $J_{E}$ and $J_{A}$}

Figure 13 shows various torque capability of the proposed single-phase 12S-6P FEFSM using segmental rotor. From the figure, the torque has increased steadily with the increase of $J_{A}$ and $J_{E}$. The torque of optimized design has increased by $80.8 \%$ from $0.91 \mathrm{Nm}$ to $1.65 \mathrm{Nm}$, achieved when maximum $J_{A}$ and $J_{E}$. At the maximum $J_{E}$ of $30 \mathrm{~A} / \mathrm{mm}^{2}$, while $\mathrm{JA}$ are set to $10 \mathrm{~A}_{\mathrm{rms}} / \mathrm{mm}^{2}$ and $20 \mathrm{~A} \mathrm{rms} / \mathrm{mm}^{2}$, the torque obtained are $0.74 \mathrm{Nm}$ and $1.32 \mathrm{Nm}$, respectively.

\subsection{Torque and Power versus Speed Characteristics}

The torque and power versus speed characteristics of the initial and optimized design of single-phase FEFSM using segmental rotor are plotted in Figure 14. From the figure, the optimized design has produced highest torque and power of $1.65 \mathrm{Nm}$ and $466.5 \mathrm{~W}$, respectively. Furthermore, the highest constant torque starts to decrease when the speed exceeds of 2,304 rpm. The motor power increases up to a maximum and start to decline when reaching the speed of 4,500 rpm with the corresponding torque of $0.99 \mathrm{Nm}$. In addition, at high speed region of $8,000 \mathrm{rpm}$, torque and power performances are $0.5 \mathrm{Nm}$ and $418.9 \mathrm{~W}$, respectively. 
Therefore, the proposed motor is considered suitable for single-phase applications requiring low torque and high speed. In short, the optimized design has succeeded in increasing torque and power to optimal performances of $81.3 \%$ and $68.2 \%$, respectively.

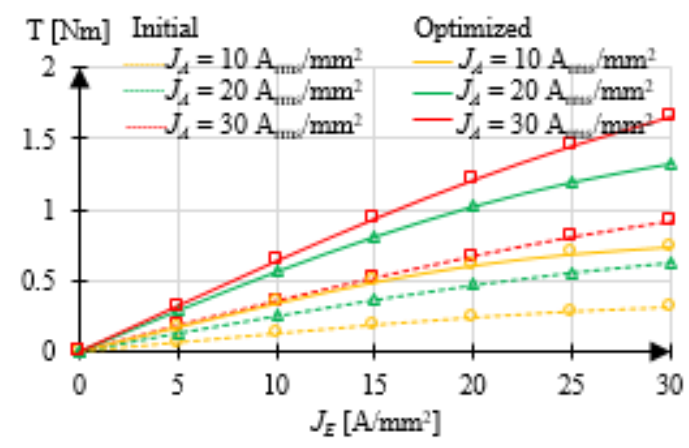

Figure 13. Torque versus $J_{E}$ at various $J_{A}$

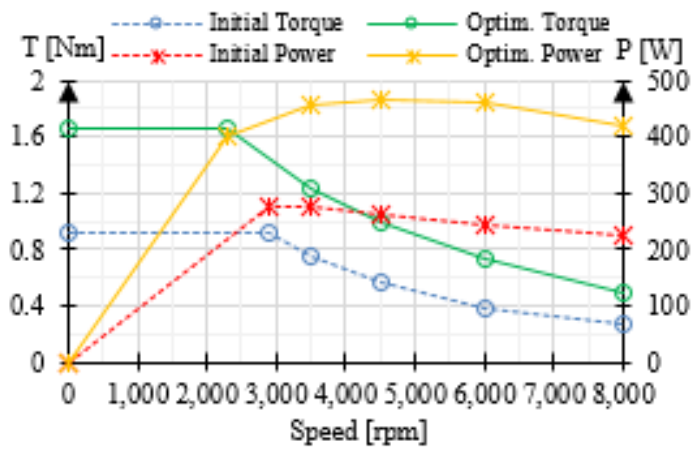

Figure 14. Torque and power versus speed

\section{CONCLUSION}

In this paper, design studies, optimization and performance analysis of single-phase 12S-6P FEFSM using segmental rotor and non-overlap windings is presented. The initial and optimized design are clearly demonstrated. Implementation of optimization using a deterministic approach to the proposed motor for optimum performances has been presented and clearly analysed. As a conclusion, the torque and power of the optimum design single-phase 12S-6P FEFSM using segmental rotor and non-overlap windings has been increased approximately by $81.3 \%$ and $68.2 \%$, respectively compared to the initial design.

\section{ACKNOWLEDGEMENTS}

This work is funded by Ministry of Education Malaysia under Fundamental Research Grant Scheme (FRGS), Vot Number 1651 and supported by Universiti Tun Hussein Onn Malaysia.

\section{REFERENCES}

[1] M. M. a Mazlan, E. Sulaiman, and T. Kosaka, "Design study of single phase outer-rotor hybrid excitation flux switching motor for hybrid electric vehicles," Proc. 2014 IEEE 8th Int. Power Eng. Optim. Conf. PEOCO 2014, no. c, pp. 138-143, 2014.

[2] E. Sulaiman, "Design Studies on Less Rare-Earth and High Power Density Flux Switching Motors with Hybrid Excitation/Wound Field Excitation for HEV Drives," 2012.

[3] H. Pollock, C. Pollock, R. T. Walter, and B. V. Gorti, "Low cost, high power density, flux switching machines and drives for power tools," IAS Annual Meeting on Conference Record of the Industry Applications Conference, 2003, pp. 1451-1457.

[4] C. Pollock and M. Wallace, "The flux switching motor, a DC motor without magnets or brushes," Conf. Rec. 1999 IEEE Ind. Appl. Conf. 34th IAS Annu. Meet., vol. 3, pp. 1980-1987, 1999.

[5] M. Jenal, S. A. Hamzah, F. Khan, H. A. Soomro, and E. Sulaiman, "Performance investigations of flux switching machines for light weight electric vehicles," IEEE Conf. Energy Conversion, CENCON 2015, pp. 78-83, 2016.

[6] C. Yu, S. Niu, S. L. Ho, and W. N. Fu, "Magnetic Circuit Analysis for a Magnetless Double-Rotor Flux Switching Motor," IEEE Trans. Magn., vol. 51, no. 11, pp. 1-4, 2015.

[7] S. M. Yang, J. H. Zhang, and J. Y. Jiang, "Modeling Torque Characteristics and Maximum Torque Control of a ThreePhase, DC-Excited Flux-Switching Machine," IEEE Trans. Magn., vol. 52, no. 7, pp. 7-10, 2016.

[8] H. Q. Nguyen, J. Y. Jiang, and S. M. Yang, "Design of a 12-slot 7-pole wound-field flux switching motor for traction applications," in IEEE International Conference on Industrial Technology (ICIT), 2016, pp. 1275-1280.

[9] E. Sulaiman, M. F. M. Teridi, Z. A. Husin, M. Z. Ahmad, and T. Kosaka, "Performance comparison of 24S-10P and 24S-14P field excitation flux switching machine with single DC-Coil polarity," in Proceedings of the 2013 IEEE 7th International Power Engineering and Optimization Conference, PEOCO, 2013, vol. 1, pp. 46-51.

[10] P. Su, W. Hua, G. Zhang, and M. Cheng, "Investigation of a novel rotor permanent magnet flux switching machine for EV and HEV applications," 2015 IEEE Int. Magn. Conf. INTERMAG 2015, vol. 50, no. 11, p. 8102405, 2015. 
[11] Y. L. Karnavas, I. D. Chasiotis, and E. D. Peponakis, "Optimization of Standard PMDC Motors used in Automotive Applications for Ǿigher Power Density," in Third International Conference on Mathematics and Computers in Sciences and in Industry (MCSI), 2016, pp. 7-13.

[12] Y. J. Zhou and Z. Q. Zhu, "Comparison of low-cost single-phase wound-field switched-flux machines," IEEE Trans. Ind. Appl., vol. 50, no. 5, pp. 3335-3345, 2014.

\section{BIOGRAPHIES OF AUTHORS}

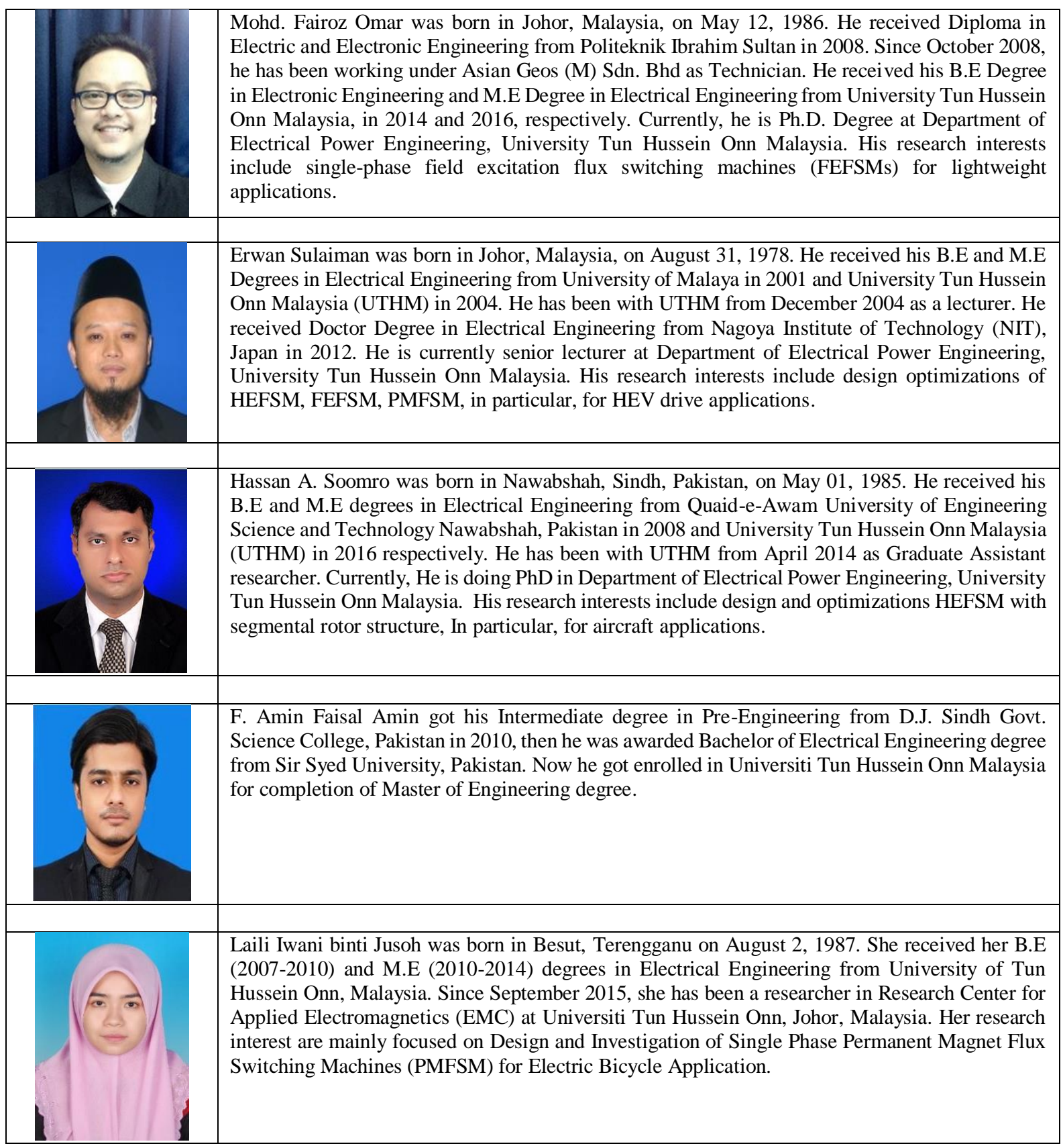

